\title{
Nano indium oxide as a recyclable catalyst for the synthesis of arylaminotetrazoles
}

\author{
SIAVASH BAHARI* and MEHDI AHMADI SABEGH \\ Department of Chemistry, Ahar Branch, Islamic Azad University, Ahar, 5451116714, Iran \\ e-mail: siavashbahari89@gmail.com; s-bahari@iau-ahar.ac.ir
}

MS received 18 February 2012; revised 17 May 2012; accepted 18 June 2012

\begin{abstract}
Nano indium oxide is an effective heterogeneous catalyst for the reaction between aryl cyanamides and sodium azide to synthesize the arylaminotetrazoles in good yields. This method has advantages of high yields, simple methodology, short reaction times and easy work-up. The catalyst can be recovered and reused in good yields.
\end{abstract}

Keywords. Arylaminotetrazole; aryl cyanamides; nano indium oxide; reusable catalyst.

\section{Introduction}

Despite the scarcity of tetrazoles in natural systems, the chemistry of this heterocycle has gained increasing attention since the early 1980s. Tetrazoles have a wide range of applications as lipophilic spacers and carboxylic acid surrogates in pharmaceuticals, as special explosives and information recording systems in materials, as ligands in coordination chemistry and as precursors to a variety of nitrogen-containing compounds. ${ }^{1-8}$

The conventional method of synthesizing tetrazoles is by addition of azide ions to organic nitriles or cyanamides. ${ }^{9-14}$ Earlier reported methods for the synthesis of arylaminotetrazoles suffer from drawbacks such as poor yield, long reaction times, harsh reaction conditions; difficulty of obtaining and/or starting materials preparation, tedious work-up, the use of expensive and toxic metal reagents, and the in situgenerated hydrazoic acid, which is highly toxic and explosive. ${ }^{15-19}$ On the other hand, in most cases only the 1-aryl-5-amino- $1 H$-tetrazoles were obtained.

Nasrollahzadeh and co-workers have shown that cyanamides may be converted to arylaminotetrazoles using $\mathrm{FeCl}_{3}-\mathrm{SiO}_{2}$ as a heterogeneous catalyst which often result in a mixture of isomers 5-arylamino$1 H$-tetrazoles (isomer $\mathbf{A}$ ) and 1-aryl-5-amino- $1 H$ tetrazoles (isomer B) (scheme 1). ${ }^{20}$

Several syntheses of arylaminotetrazoles have been reported through the $[2+3]$ cycloaddition of cyanamides using $\mathrm{NaN}_{3}$ in the presence of catalysts

*For correspondence such as natrolite zeolite (local zeolite) ${ }^{21}$ and $\mathrm{ZnCl}_{2} \cdot{ }^{22}$ The development of a catalytic synthetic method for tetrazoles still remains an active research area.

In recent years there has been a tremendous interest in various chemical transformations performed under the heterogeneous catalysis. Among heterogeneous catalysts, metal nanoparticles have been used widely as efficient catalysts in organic reactions due to their high catalytic activity, ease of handling, reusability, and benign character. ${ }^{23-28}$ Indium (III) compounds are mild and water-tolerant Lewis acids and show high regio-, stereo-, and chemoselectivity. ${ }^{29-33}$ However, until now the use of nano $\operatorname{In}_{2} \mathrm{O}_{3}$ as a catalyst is limited in organic synthesis. $^{34}$

Here, we describe an efficient method for the preparation of arylaminotetrazoles using nano $\mathrm{In}_{2} \mathrm{O}_{3}$ as a heterogeneous catalyst (scheme 2).

\section{Experimental}

\subsection{General}

All reagents were purchased from Merck and Aldrich chemical companies and used without further purification. Products were characterized by FT-IR, ${ }^{1} \mathrm{H}$ NMR and ${ }^{13} \mathrm{C}$ NMR, elemental analysis (CHN), and melting points. ${ }^{1} \mathrm{H}$ NMR spectra were recorded on Bruker Avance DRX 250, 300 and $500 \mathrm{MHz}$ instruments. NMR spectra were recorded in $\mathrm{CDCl}_{3}, \mathrm{DMSO}-d_{6}$ and acetone- $d_{6}$. Chemical shifts $(\delta)$ are reported in ppm relative to tetramethylsilane (TMS) as internal standard. $\mathbf{J}$ values are given in $\mathrm{Hz} .{ }^{13} \mathrm{C}$ NMR spectra were recorded at 125 and $75 \mathrm{MHz}$. FT-IR (KBr) spectra 


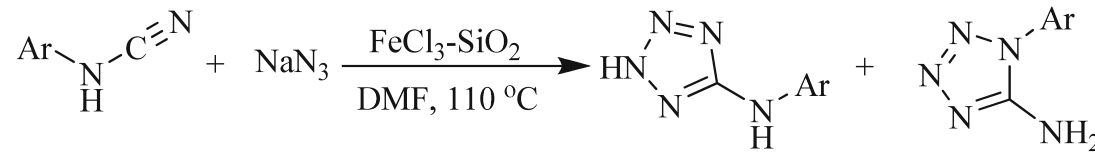

$$
\begin{aligned}
& \text { Isomer A Isomer B }
\end{aligned}
$$

Scheme 1. Synthesis of arylaminotetrazoles by the $\mathrm{FeCl}_{3}-\mathrm{SiO}_{2}$.

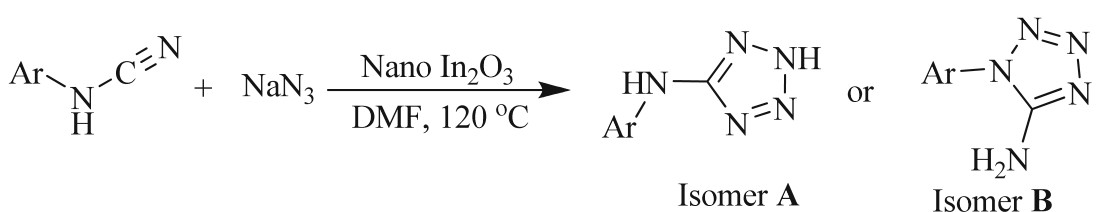

Scheme 2. Synthesis of arylaminotetrazoles by the nano $\operatorname{In}_{2} \mathrm{O}_{3}$.

were recorded on PerkinElmer 781 spectrophotometers. apparatus and are uncorrected. Thin-layer chromatogMelting points were obtained on a Reichert 7905 hot- raphy (TLC) was performed on silica gel polygram SIL stage microscope or an Electrothermal IA9000 capillary G/UV 254 plates.

\begin{tabular}{|c|c|c|c|c|c|c|}
\hline Entry & $\mathrm{Ar}$ & Product & $3(\mathbf{A}$ or $\mathbf{B})$ & Time (min) & Yield $\%$ & m.p. $\left({ }^{\circ}\right)\left[\right.$ lit. $\left.\mathrm{mp}^{\mathrm{ref}}\right]$ \\
\hline 1 & $4-\mathrm{NO}_{2}-\mathrm{C}_{6} \mathrm{H}_{4}$ & & 3a $(\mathbf{A})$ & 110 & 81 & $218-220\left[218-220^{21}\right]$ \\
\hline 2 & $2,5-(\mathrm{Cl})_{2}-\mathrm{C}_{6} \mathrm{H}_{3}$ & & $3 \mathbf{b}(\mathbf{A})$ & 110 & 80 & $272-274\left[273-274^{21}\right]$ \\
\hline 3 & & & $3 \mathrm{c}(\mathrm{A})$ & 100 & 82 & $214-215\left[215-217^{21}\right]$ \\
\hline 4 & $2,6-(\mathrm{Me})_{2}-\mathrm{C}_{6} \mathrm{H}_{3}$ & & 3d (B) & 60 & 86 & $148-150\left[147-149^{22 b}\right]$ \\
\hline 5 & 4-Me- $\mathrm{C}_{6} \mathrm{H}_{4}$ & & $3 \mathbf{e}(\mathbf{B})$ & 60 & 80 & $177-178\left[175.5-177^{16}\right]$ \\
\hline 6 & 2-Me- $\mathrm{C}_{6} \mathrm{H}_{4}$ & & $\mathbf{3 f}(\mathbf{B})$ & 60 & 84 & $191-192\left[191-192^{21}\right]$ \\
\hline 7 & $2,4-(\mathrm{Me})_{2}-\mathrm{C}_{6} \mathrm{H}_{3}$ & & $3 \mathbf{g}(\mathbf{B})$ & 60 & 83 & $199-201\left[199-201^{21}\right]$ \\
\hline 8 & $1,4-\mathrm{C}_{6} \mathrm{H}_{4}$ & & $3 \mathbf{h}(\mathbf{B})$ & 55 & 84 & $220-221\left[220-221^{14 c}\right]$ \\
\hline
\end{tabular}

Table 1. Synthesis of arylaminotetrazoles (3) via secondary aryl cyanamides (1) catalysed by nano $\operatorname{In}_{2} \mathrm{O}_{3}$.

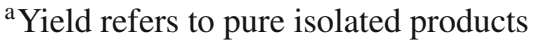




\subsection{General procedure for the synthesis of arylaminotetrazoles}

Nano $\mathrm{In}_{2} \mathrm{O}_{3}(0.1 \mathrm{~g})$ was added to a mixture of cyanamides $(\mathbf{1 a}-\mathbf{h})(2 \mathrm{mmol}), \mathrm{NaN}_{3}(0.2 \mathrm{~g}, 3 \mathrm{mmol})$ in distilled dimethylformamide $(5 \mathrm{~mL})$ and stirred at $120^{\circ} \mathrm{C}$ for the appropriate time (table 1). After completion of the reaction (as monitored by TLC), the catalyst was centrifuged, washed with ethyl acetate and the centrifugate was treated with ethyl acetate $(35 \mathrm{~mL})$ and $5 \mathrm{~N} \mathrm{HCl}(20 \mathrm{~mL})$. The resultant organic layer was separated and the aqueous layer was again extracted with ethyl acetate $(20 \mathrm{~mL})$. The combined organic layers were washed with water, concentrated, and washed with ethanol to give different arylaminotetrazoles. The physical data (mp, IR, NMR) of known compounds were found to be identical to those reported in the literature. ${ }^{21,22}$

5-Arylamino- $1 H$-tetrazoles isomers (A) contain two $\mathrm{NH}$ bonds ( $\mathrm{NH}$ of the amine attached to the aryl group $\left(\mathrm{NH}^{\mathrm{A}}\right)$ and $\mathrm{NH}$ of the tetrazole ring $\left(\mathrm{NH}^{\mathrm{T}}\right)$ ) and 1-aryl-5-amino-1 $\mathrm{H}$-tetrazoles isomers $(\mathbf{B})$ contain a $\mathrm{NH}_{2}$ bond. The disappearance of one strong and sharp absorption band ( $\mathrm{CN}$ stretching band) and the appearance of a NH stretching band in the IR spectra provided clear evidence for the formation of arylaminotetrazoles. ${ }^{13} \mathrm{C}$ NMR spectra displayed signals at $\delta=154-157.5 \mathrm{ppm}$, indicative of C5 in the tetrazole ring. ${ }^{21,22}$

2.2a 1-(2,6-Dimethylphenyl)-5-amino-1H-tetrazole (3d): M.P. 148-150 ; FT-IR (KBr): 3441, 3383, 3351, 2952, 2921, 1697, 1651, 1604, 1583, 1558, 1526, 1486, 1442, 1247, 1228, 1194, 1168, 1032, 987, 938, $780 \mathrm{~cm}^{-1} ;{ }^{1} \mathrm{H}-\mathrm{NMR}\left(500 \mathrm{MHz}, \mathrm{DMSO}-d_{6}, \delta /\right.$ ppm): $1.92(6 \mathrm{H}, \mathrm{s}), 6.67(2 \mathrm{H}, \mathrm{s}), 7.30$ (d, $J=7.7 \mathrm{~Hz}$,
2H), $7.42(\mathrm{t}, J=7.7 \mathrm{~Hz}, 1 \mathrm{H}) ;{ }^{13} \mathrm{C}$ NMR $(125 \mathrm{MHz}$, DMSO- $\left.d_{6}\right)$ : $16.8,125.2,128.3,135.9,136.0,155.2$; Anal. Calcd for $\mathrm{C}_{9} \mathrm{H}_{11} \mathrm{~N}_{5}$ : C, 57.12; H, 5.86; N, 37.02. Found: C, 57.19; H, 5.91; N, 37.09.

\section{Results and discussion}

The cyanamides were prepared according to the literature. ${ }^{14 \mathrm{~b}}$ The general synthetic method is depicted in scheme 1. Arylaminotetrazoles were obtained from the reaction of cyanamides with sodium azide in the presence of nano $\mathrm{In}_{2} \mathrm{O}_{3}$ as an efficient heterogeneous catalyst at $120^{\circ}$ for the appropriate time in good yields (table 1).

To show the advantages of nano $\operatorname{In}_{2} \mathrm{O}_{3}$, its reaction was compared with $\mathrm{FeCl}_{3}-\mathrm{SiO}_{2}$, glacial HOAc, $\mathrm{ZnCl}_{2}$ and Natrolite zeolite in the synthesis of 5-(2,5dichlorophenyl)amino- $1 H$-tetrazole $(\mathbf{3 c})$. As shown in table 2, nano $\operatorname{In}_{2} \mathrm{O}_{3}$ is an effective catalyst since the products are regiospecific, whereas with $\mathrm{FeCl}_{3}-\mathrm{SiO}_{2}$ and glacial HOAc, a mixture of isomers will be produced. $\mathrm{ZnCl}_{2}{ }^{22}$ is homogeneous which cannot be separated from the reaction mixture, while nano $\mathrm{In}_{2} \mathrm{O}_{3}$ is heterogeneous and can easily be recovered and reused. Natrolite zeolite ${ }^{21}$ is a good catalyst, but there are difficulties in the preparation and availability of catalyst. Not many organic solvents are suitable for the cycloaddition reactions which usually need high temperatures (sometimes as high as $130^{\circ}$ ), and so DMF is a most commonly used solvent for this purpose. ${ }^{2,20,21}$ The optimum amount of nano $\operatorname{In}_{2} \mathrm{O}_{3}$ was found to be $0.1 \mathrm{~g}$ in the presence of cyanamide $(2 \mathrm{mmol})$ and sodium azide (3 mmol) in DMF $(6 \mathrm{~mL})$. We have also examined a variety of structurally divergent phenylcyanamide possessing a wide range of functional groups to understand the scope and generality of nano $\operatorname{In}_{2} \mathrm{O}_{3}$-promoted

Table 2. Comparison of nano $\mathrm{In}_{2} \mathrm{O}_{3}$ activity with other reagents in the synthesis of arylaminotetrazoles.

\begin{tabular}{lccccc}
\hline Entry & Catalyst & Solvent & Time $(\min )$ & Yield $^{\mathrm{a}} \%$ & Product (A or B) \\
\hline 1 & $\mathrm{FeCl}_{3}-\mathrm{SiO}_{2}(0.1 \mathrm{~g})$ & $\mathrm{DMF}^{\mathrm{b}}$ & 120 & 76 & $\mathbf{A}+\mathbf{B}$ \\
2 & $\mathrm{Glacial} \mathrm{HOAc}(3 \mathrm{~mL})^{\mathrm{H}}$ & $\mathrm{Glacial} \mathrm{HOAc}^{\mathrm{c}}$ & $30 \mathrm{~h}^{\mathrm{d}}$ & 72 & $\mathbf{A}+\mathbf{B}$ \\
3 & $\mathrm{ZnCl}_{2}(0.4 \mathrm{~g})$ & $\mathrm{H}_{2} \mathrm{O}^{\mathrm{e}}$ & $15 \mathrm{~h}$ & 84 & $\mathbf{A}$ \\
4 & Natrolite zeolite $(0.1 \mathrm{~g})$ & $\mathrm{H}_{2} \mathrm{O}^{\mathrm{e}}$ & $9 \mathrm{~h}$ & 49 & $\mathbf{A}$ \\
5 & Natrolite zeolite $(0.1 \mathrm{~g})$ & $\mathrm{DMF}^{\mathrm{f}}$ & 95 & 81 & $\mathbf{A}$ \\
6 & Nano $\mathrm{In}_{2} \mathrm{O}_{3}(0.05 \mathrm{~g})$ & $\mathrm{DMF}$ & 120 & 69 & $\mathbf{A}$ \\
7 & Nano $\mathrm{In}_{2} \mathrm{O}_{3}(0.07 \mathrm{~g})$ & $\mathrm{DMF}$ & 120 & 73 & $\mathbf{A}$ \\
8 & $\mathrm{Nano} \mathrm{In}_{2} \mathrm{O}_{3}(0.10 \mathrm{~g})$ & $\mathrm{DMF}$ & 120 & 80 & $\mathbf{A}$ \\
9 & Nano $\mathrm{In}_{2} \mathrm{O}_{3}(0.10 \mathrm{~g})$ & $\mathrm{DMSO}$ & 120 & 80 & $\mathbf{A}$ \\
10 & Nano $\mathrm{In}_{2} \mathrm{O}_{3}(0.15 \mathrm{~g})$ & DMF & 120 & 81 & $\mathbf{A}$ \\
\hline
\end{tabular}

${ }^{\mathrm{a}}$ Isolated yield. ${ }^{\mathrm{b}}$ Under thermal conditions at $110^{\circ} .{ }^{\mathrm{c}}$ Glacial acetic acid as both solvent and proton source. ${ }^{\mathrm{d}}$ Room temperature. ${ }^{\mathrm{e}}$ Under reflux conditions. ${ }^{\mathrm{f}}$ Under thermal conditions at $110-115^{\circ}$ 
cycloaddition reaction to form arylaminotetrazoles and the results are summarized in table 1 .

The products were completely regiospecific. This observation is in contrast with those reports that the other reagents will often produce a mixture of isomers (scheme 3).

As shown in table 1, cyanamides having methyl as an electron releasing group (entries 4-7) were completed at $120^{\circ}$ after $60 \mathrm{~min}$, while the species bearing the electron withdrawing groups $\mathrm{NO}_{2}$ or $\mathrm{Cl}$ (entries 1-2) require higher reaction times.

The influences of various substituents in different ortho, meta or para positions on the type of products were examined. Generally, when the substituent on the aryl ring of $\mathbf{1}$ is electron-releasing, formation of 1-aryl5-amino- $\mathrm{H}$-tetrazoles $(\mathbf{B})$ is favoured via the guanidine azide intermediate $\mathbf{B}^{\prime}$ (table 1, entries 4, 5, 6 and 7 ), while with electron-withdrawing substituents the product is shifted toward the formation of 5-arylamino$1 H$-tetrazoles (A) via the guanidine azide intermediate $\mathbf{A}^{\prime}$ (table 1, entries 1 and 2). In the earlier research carried out, the nature of the substituent did not have any effect. ${ }^{15-17,35-37}$ In the previously reported methods, substituents as different in their electrical effects as the methyl group and the $p$-nitrophenyl group permit the formation of the same type of compound (isomer B). ${ }^{17}$ No clear explanation was given by the previous workers about the isolation or detection of other isomers, although Stolle and Heintz reported the isolation of 5-anilinotetrazole in low yield from the reaction of phenylthiourea with lead oxide and sodium azide. ${ }^{38}$ In other words, in the synthesis of aminotetrazoles from cyanamides, only the 1-aryl-5-amino-1 $H$-tetrazole (B) or a mixture of isomers $(\mathbf{A}+\mathbf{B})$ was obtained (scheme 4). ${ }^{13,20}$

Due to the presence of two CN groups, $\mathbf{1} \mathbf{h}$ (table 1, entry 8) interestingly afforded the double-addition product.

4-Nitrophenylcyanamide interestingly gave 5-(4nitrophenyl)amino- $1 H$-tetrazole (isomer $\mathbf{A}$ ), while with

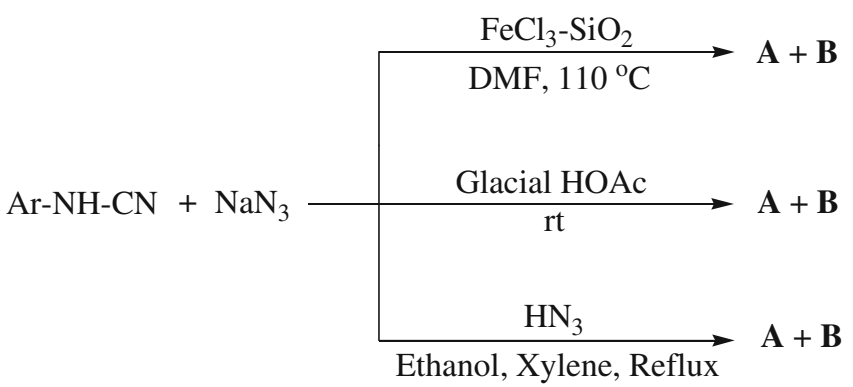

Scheme 3. Synthesis of arylaminotetrazoles under different conditions.

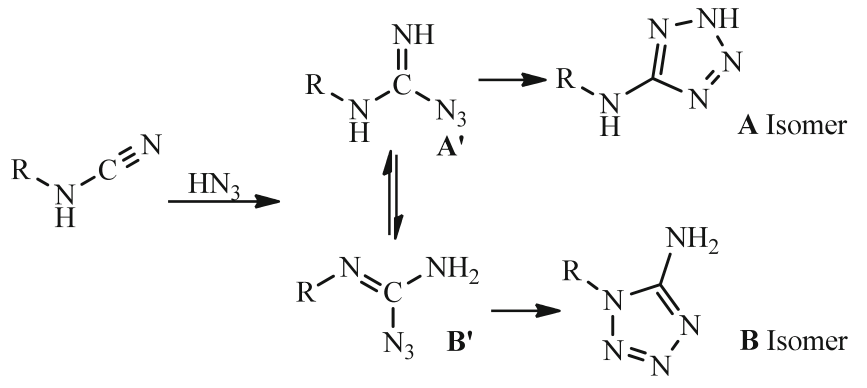

Scheme 4. Synthesis of arylaminotetrazoles by the hydrazoic acid.

$\mathrm{HN}_{3}, \mathrm{FeCl}_{3}-\mathrm{SiO}_{2}$ and glacial HOAc, 1-(4-nitrophenyl)5-amino- $1 H$-tetrazole (isomer $\mathbf{B}$ ) or a mixture of isomers $(\mathbf{A}+\mathbf{B})$ was obtained.

The mechanism of the catalysis may originate from the nitrile group coordinating with the surface of the solid acid. The solid acid is supposed to activate the nitriles and enhance their reactivity with sodium azide. However, further experiments are necessary to gain a clearer insight into these reactions.

The catalyst recycling is an important step as it reduces the cost of the process. Nano $\operatorname{In}_{2} \mathrm{O}_{3}$ was recovered quantitatively by simple centrifugation and reused for three cycles with consistent activity. This reusability demonstrates the high stability and turnover of nano $\mathrm{In}_{2} \mathrm{O}_{3}$ under operating conditions.

\section{Conclusion}

We have developed a simple and efficient method for the synthesis of arylaminotetrazoles by treatment of cyanamides with sodium azide in the presence of nano $\mathrm{In}_{2} \mathrm{O}_{3}$ as an effective heterogeneous catalyst. The significant advantages of this methodology are high yields, elimination of dangerous and harmful hydrazoic acid, a simple work-up procedure, and easy preparation and handling of the catalyst. The catalyst can be recovered by filtration and reused.

\section{Acknowledgements}

We are thankful to the Islamic Azad University, Ahar Branch for partial financial support to carry out this research work.

\section{References}

1. Bulter R N 1996 In: Comprehensive heterocyclic chemistry II; A R Katritzky, C W Ress and E F V Scriven (eds) New York: Pergamon 4621

2. Herr R 2002 J. Bioorg. Med. Chem. 103379

3. Holland G F and Pereira J N 1967 J. Med. Chem. 10149 
4. Figdor S K and Schach von Wittenau M 1967 J. Med. Chem. 101158

5. Rhonnstad P and Wensbo D 2002 Tetrahedron Lett. 43 3137

6. Klapötke T M, Stierstorfer J and Weber B 2009 Inorg. Chim. Acta 3622311

7. John E O, Kirchmeier R L and Shreeve J M 1989 Inorg. Chem. 284629

8. Modarresi-Alam A R, Khamooshi F, Rostamizadeh M, Keykha H, Nasrollahzadeh M, Bijanzadeh H R and Kleinpeter E 2007 J. Mol. Struc. 84161

9. Kadaba P K 1973 Synthesis 71

10. Wittenberger S J 1994 Org. Prep. Proc. Int. 26499

11. Curran D P, Hadida S and Kim S Y, 1999 Tetrahedron 558997

12. Huff B E and Staszak M A 1993 Tetrahedron Lett. 34 8011

13. Modarresi-Alam A R and Nasrollahzadeh M 2009 Turk. J. Chem. 33267

14. (a) Nasrollahzadeh M, Bayat Y, Habibi D and Moshaee S 2009 Tetrahedron Lett. 50 4435; (b) Habibi D and Nasrollahzadeh M 2012 Monatsh Chem. 143 925; (c) Habibi D, Nasrollahzadeh M, Bayat Y 2011 Synth. Commun. 41 2135; (d) Habibi D, Nasrollahzadeh M, Kamali T A 2011 Green Chem. 13 3499; (e) Habibi D and Nasrollahzadeh M 2012 Synth. Commun. 422023

15. Finnegan W G, Henry R A and Lieber E 1953 J. Org. Chem. 18779

16. Henry R A, Finnegan W G and Lieber E 1954 J. Am. Chem. Soc. 7688

17. Garbrecht W L and Herbst R M 1953 J. Org. Chem. 18 1014

18. M S Congreve 1996 Synlett. 359

19. Vorobiev A N, Gaponik P N, Petrov P T, Vestsi Nats. Akad. Navuk Belarusi, Ser. Khim. Navuk; 2003, No. 2, 50, 2004 Chem. Abstr. 140 16784g

20. Habibi D and Nasrollahzadeh M 2010 Synth. Commun. 403159

21. Nasrollahzadeh M, Habibi D, Shahkarami Z and Bayat Y 2009 Tetrahedron 5110715

22. (a) Habibi D, Nasrollahzadeh M, Faraji A R and Bayat Y 2010 Tetrahedron 66 3866; (b) Habibi D, Nasrollahzadeh M, Sahebekhtiari H and Sajadi S M 2012 Synlett 232795

23. (a) Mohammadi B, Hosseini Jamkarani S M, Kamali T A, Nasrollahzadeh M, Mohajeri A 2010 Turk. J.
Chem. 34 613; (b) Modarresi-Alam A R, Nasrollahzadeh M, Khamooshi F 2007 Arkivoc xvi 234; (c) ModarresiAlam A R, Khamooshi F, Nasrollahzadeh M, Amirazizi H A 2007 Tetrahedron 63 8723; (d) Modarresi-Alam A R, Nasrollahzadeh M, Khamooshi F 2008 Sci. Iran. 15 452; (e) Modarresi-Alam A R, Khamooshi F, Nasrollahzadeh M, Amirazizi H A 2008 Tetrahedron 64 4656; (f) Habibi D, Heydari S and Nasrollahzadeh M 2012 J. Chem. Res. 36 573; (g) Habibi D, Nasrollahzadeh M, Mehrabi L and Mostafaee S 2012 Monatsh fur Chem. doi:10.1007/s00706-012-0871-9; (h) Habibi D, Nabavi H, Nasrollahzadeh M 2013 J. Chem. Article ID 645313; (i) Bahari S, MohammadiAghdam B, Molaei R, Gharibi Z 2012 Can. J. Chem. 90 784; (j) Bahari S, Mohammadi-Aghdam B, Sajadi S M, Zeidali F 2012 Bull. Korean Chem. Soc. 332251

24. (a) Astruc D, Lu F and Aranzaes J R 2005 Angew. Chem., Int. Ed. 44 7852; (b) Polshettiwar V, Baruwati B and Varma R S 2009, Green Chem. 11127

25. Adak L, Chattopadhyay K and Ranu B C 2009 J. Org. Chem. 743982

26. Dey R, Chattopadhyay K and Ranu B C 2008 J. Org. Chem. 739461

27. Jammi S, Sakthivel S, Rout T, Mandal S, Mitra R, Saha P and Punniyamurthy T 2009 J. Org. Chem. 741971

28. Zhang W, Zhang X, Tian Y, Yue Y, Guo Y and Wang Z 2011 J. Org. Chem. 764741

29. Ghosh R and Maiti S 2007 J. Mol. Catal. A: Chem. 2641

30. Nair V, Ros S, Jayan C N and Pillai B S 2004 Tetrahedron 601959

31. Kundu D, Majee A and Hajra A 2009 Tetrahedron Lett. 502668

32. Ranu B C, Dey S S and Hajra A 2002 Tetrahedron 58 2529

33. Ranu B C, Hajra A and Jana U 2002 Tetrahedron Lett. 41531

34. Reddy V P, Kumar A V, Swapna K and Rao K R 2009 Org. Lett. 111697

35. Henry R A, Finneganand W G and Lieber E $1955 \mathrm{~J}$. Am. Chem. Soc. 772264

36. Garbrecht W L and Herbst R M 1953 J. Org. Chem. 18 1003

37. Garbrecht W L and Herbst R M 1953 J. Org. Chem. 18 1022

38. Stolle R and Heintz K 1937 J. Prakt. Chem. 147286 